\title{
A (RE)CONSTRUÇÃO DO ETHOS DE NARUTO UZUMAKI
}

\section{THE (RE)CONSTRUCTION OF NARUTO UZUMAKI'S ETHOS}

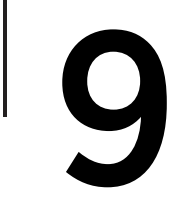

SILVA, GUILHERME MATHEUS DA

GRADUANDO EM LETRAS - PORTUGUÊS/ ESPANHOL DA UNIVERSIDADE FEDERAL DE SÃO PAULO (UNIFESP), GUARULHOS, SP, BRASIL. PESQUISADOR EM NÍVEL DE INICIAÇÃO CIENTÍFICA.

E-MAIL: GUILHERME.MATHEUS31@HOTMAIL.COM

ORCID: HTTPS://ORCID.ORG/0000-0002-1972-5162

\section{CARMELINO, ANA CRISTINA}

DOUTORA EM LINGUÍSTICA E LÍNGUA PORTUGUESA PELA UNIVERSIDADE ESTADUAL PAULISTA "JÚLIO DE MESQUITA FILHO" (UNESP/CAR).

PROFESSORA DO DEPARTAMENTO DE LETRAS DA UNIVERSIDADE FEDERAL DE SÃO PAULO (UNIFESP), GUARULHOS, SP, BRASIL.

E-MAIL: ANACRISCARMELINO@GMAIL.COM

ORCID: HTTPS://ORCID.ORG/0000-0002-7576-0595

\section{RESUMO}

O presente artigo tem como finalidade mostrar como se efetiva a mudança dos ethé, de negativo para positivo, de Naruto Uzumaki, personagem principal da série Naruto (2007), considerando sua relevância no anime. A metodologia adotada será a captura, pelos stills dos vídeos, de sete cenas e a transcrição dos discursos com base nas normas do NURC/SP (CASTILHO; PRETI, 1986). O sucesso da série, segundo entendemos, deve-se à personalidade forte e à coragem do protagonista, elementos que sustentam a persuasão da trama. A análise fundamentase nos pressupostos teóricos da Retórica clássica (ARISTÓTELES, 2015), da Nova Retórica (PERELMAN; OLBRECHTS-TYTECA, 2005; REBOUL, 2004; MEYER, 2007; FERREIRA, 2010; FIORIN, 2015) e da Análise do Discurso (MAINGUENEAU, 2008), respaldando-se especificamente na noção de ethos.

Palavras-chave: Ethos; Naruto; Anime. 


\section{ABSTRACT}

The purpose of this article is to show how the change of ethé, from negative to positive, of Naruto Uzumaki, main character of the Naruto series (2007), is effective, considering their relevance in anime. The methodology adopted will be the capture, by the stills of the videos, of seven scenes and the transcription of the speeches based on the norms of NURC / SP (CASTILHO; PRETI, 1986). The success of the series, as we understand it, is due to the strong personality and courage of the protagonist, elements that support the persuasion of the plot. The analysis is based on the theoretical assumptions of classical Rhetoric (ARISTÓTELES, 2015), New Rhetoric (PERELMAN; OLBRECHTS-TYTECA, 2005; REBOUL, 2004; MEYER, 2007; FERREIRA, 2010; FIORIN, 2015) and Discourse Analysis (MAINGUENEAU, 2008), specifically supporting the notion of ethos.

Keywords: Ethos; Naruto; Anime.

\section{CONSIDERAÇÕES INICIAIS}

Desde que surgiram, os mangás e suas adaptações em animes têm ganhado uma notável relevância no mundo contemporâneo (cf. BRENNER, 2007). A criação desses quadrinhos traz à tona a arte e as tradições culturais do Japão. Os mangás são histórias sequenciais bem definidas, a princípio produzidas por imagens. Embora não seja possível precisar ao certo quando foram criados os mangás, segundo Brenner (2007), estima-se que os primeiros esboços dessas obras sejam de meados dos séculos XII, registrados em pergaminhos chamados de "Choju Giga", os quais apresentavam ilustrações de diversos animais, criados pelos monges budistas da época.

Brenner (2007, p. 2) destaca que o termo "mangá" foi reconhecido pelo artista japonês Hokusai Katsushika, cujas obras artísticas retratavam a tradicional forma popular ukiyo-e, traduzido para o português como "imagens do mundo flutuante", um estilo de pintura xilográfico que representava a beleza feminina, dentre outros aspectos. As obras de Katsuhika propagaram-se rapidamente, tornando os quadrinhos famosos, o que impactou a cultura Ocidental.

Os efeitos dessas obras resultaram em um sucesso mundial, o que contribuiu significativamente para a propagação no âmbito cinematográfico. As adaptações dos quadrinhos em animações revelam notável poder persuasivo, tendo em vista a conquista de inúmeros fãs, 
como afirma Martins (2018). É com base no alcance persuasivo das adaptações de mangás em anime que este texto toma como objeto de estudo "Naruto", série popular criada em 2007, por Masashi Kishimoto. O objetivo principal é verificar como se dá a construção e a reconstrução do ethos do protagonista, Naruto Uzumaki.

A análise fundamenta-se na noção de ethos, vista à luz dos pressupostos teóricos da Retórica clássica (ARISTÓTELES, 2015), da Nova Retórica (PERELMAN; OLBRECHTS-TYTECA, 2005; REBOUL, 2004; MEYER, 2007; FERREIRA, 2010; FIORIN, 2015) e da Análise do Discurso (MAINGUENEAU, 2008). A metodologia adotada na análise dos dados é a captura de sete cenas pelos stills dos vídeos bem como a transcrição dos discursos das cenas selecionadas com base nas normas do NURC/ SP (CASTILHO; PRETI, 1986). O estudo revela que o protagonista se vale majoritariamente das características do ethos para angariar respeito.

A propósito de tornar clara a exposição dos dados, este artigo se configura da seguinte forma: primeiro, a fim de compreender como a mudança do ethos do protagonista se efetiva, faz-se necessário tratar na noção ethos pelo viés dos autores da Retórica, da Nova Retórica e da Análise do Discurso; em seguida, parte-se para a contextualização do objeto da análise, a série Naruto; e, por último, apresenta-se a análise das cenas que compõem o corpus do estudo deste texto.

\section{A NOÇÃO DE ETHOS SOB O OLHAR DA RETÓRICA E DA ANÁLISE DO DISCURSO}

Desde seu surgimento, a Retórica, que se ocupa dos métodos persuasivos, apresenta grande relevância nos estudos contemporâneos. Segundo Aristóteles (2015, p. 14), a "retórica é, pois, uma forma de comunicação, uma ciência que se ocupa dos princípios e das técnicas de comunicação [...] que tem fins persuasivos". Para o filósofo, há três provas que tornam o discurso efetivo, são elas: logos, pathos e ethos. No caso, o pathos se refere às paixões, às emoções que o orador pode despertar em seu auditório; o logos corresponde à parte racional do discurso, da construção lógica dos argumentos; já o ethos relaciona-se à imagem que o orador produz de si. Na concepção aristotélica, o ethos é uma das principais provas retóricas no processo de persuasão.

Sendo a prova do ethos o foco deste estudo, passemos a tratar dela com mais profundidade. De acordo com Aristóteles (2015, p. 63), "persuade-se pelo caráter quando o discurso é proferido de tal maneira que deixa a impressão do orador ser digno de fé". Nessa passagem, 
verifica-se que a persuasão do auditório se dá pelo discurso que o orador profere, pois é nesse momento que ele cria uma imagem (ethos) na qual seus ouvintes possam depositar confiança, seja ela verdadeira ou não. O filósofo trata de três características inerentes ao ethos que o orador necessita adquirir para conquistar a adesão do auditório por meio do discurso, a saber: phrónesis (sabedoria), areté (virtude) e eúnoia (benevolência). É por meio dessas três disposições que o orador demonstra ser ponderado, justo e simpático.

A concepção de ethos trabalhada na retórica aristotélica deu origem a uma série de estudos abordados por autores que ampliaram esse conceito, caso de autores da chamada Nova Retórica. É o que fazem Perelman e Olbrechts-Tyteca (2005, p. 27), que destacam a importância do auditório para a construção dessa imagem, como se pode observar no excerto em que afirmam "É, de fato, ao auditório que cabe o papel principal para determinar a qualidade da argumentação e o comportamento dos oradores". Isso posto, salienta-se a importância do conhecimento do auditório a quem o orador se dirige com o intuito de persuadir, para formulação de argumentos convincentes.

Tomando como base os pressupostos aristotélicos, Reboul (2004, p. 48) afirma que "etos é um termo moral, 'ético', e que é definido como o caráter moral que o orador deve parecer ter, mesmo que não o tenha deveras". O orador, assim, persuade pela imagem verossímil criada em seu discurso, com o propósito de convencer. O auditório será persuadido por essa verossimilhança, a partir do momento em que o orador mostrar ser sensato, sincero e simpático, que equivalem às três qualidades do ethos tratadas por Aristóteles.

Partindo das concepções aristotélicas a respeito dessas três características inerentes ao ethos, Fiorin (2015, p. 71) busca ampliá-las, como se observa em:

a) a phrónesis, que significa o bom senso, a prudência, a ponderação, ou seja, que indica se o orador exprime opiniões competentes e razoáveis ; b) a areté, que denota virtude, mas virtude tomada no seu sentido primeiro de "qualidades distintivas do homem", portanto a coragem, a justiça, a sinceridade, o orador apresenta-se como alguém simples e sincero, franco ao expor seu ponto de vista; c) a eúnoia, que significa a benevolência e a solidariedade; nesse caso, o orador dá uma imagem agradável de si porque mostra simpatia pelo auditório. 
Para o escritor e filósofo belga Meyer (2007, p. 34), o ethos está ligado à ética, pois a noção vai além da imagem que o orador cria no discurso, é o que se verifica em "o ethos é a imagem de si, o caráter, a personalidade, os traços de comportamento, a escolha de vida e dos fins". De acordo com seus pressupostos, que partem da problematologia, o ethos contém em essência o ponto final de qualquer questionamento que o auditório possa formular, a partir do qual o orador deve ser capaz de suprimir tais questões.

O referido autor ainda apresenta o fenômeno "como aquele ou aquela com quem o auditório se identifica, o que tem como resultado conseguir que suas respostas sobre a questão tratada sejam aceitas" (MEYER, 2007, p. 35). Nessa perspectiva, a imagem exemplar, digna de ser seguida, que o orador cria de si, na qual seus ouvintes possam se identificar, poderá determinar o comportamento do auditório e a aceitação de seu discurso.

Meyer (2007) amplia o conceito de ethos, propondo dois tipos: o projetivo e o efetivo. O ethos projetivo ou imanente refere-se à imagem previamente formulada do pathos (auditório) sobre o orador. Já o ethos efetivo ou não-imanente relaciona-se à imagem de fato construída pelo orador, com o intuito de persuadir. Dessa forma, o orador pode trabalhar a seu favor os ethé para conquistar seu público, como se observa em "O autor pode jogar com a defasagem entre esses dois ethos, ou, ao contrário, com a identidade entre eles a fim de manipular o auditório" (MEYER, 2007, p. 36).

Ferreira (2010, p. 90) alarga a noção do ethos aristotélico para além da imagem construída pelo orador em seu discurso, uma vez que o autor afirma que "(...) hoje se aceita como ethos a imagem que o orador constrói de si e dos outros no interior do discurso". Assim, para atingir os objetivos de persuadir por meio de seu discurso, o orador cria não somente sua imagem, como também a imagem do outro. Para isso, o orador deve se adaptar segundo os costumes e os ideais do auditório. Com base nos pressupostos de Aristóteles e na leitura de Eggs (2005) sobre o tema, Ferreira (2019, p. 16) também aprofunda considerações sobre as características do ethos, como se verifica em:

No ato retórico, a demonstração da phrónesis indica que o orador estabelece raciocínios sobre as "realidades" que poderiam ser diferentes e desvela uma "verdade" construída no e pelo discurso. O discernimento, assim, é qualidade racional que leva à crença em uma dada "verdade" quando 
os argumentos se concentram nas ações relacionadas com os bens humanos. Por isso, a phrónesis vale-se de uma explícita demonstração de inteligência (valor cognitivo) aliada a um projeto prático de mover o auditório. a.2. Areté é a virtude, a disposição que faz um homem bom e o leva a desempenhar sua função com retidão e probidade. Nesse sentido, o homem virtuoso cumpre o ato determinado, conhece o que faz e o executa voluntariamente como resultado de uma disposição permanente. a.3. Eúnoia é a benevolência. No exercício de ser e parecer no discurso, a generosidade, o altruísmo, a condescendência e a magnanimidade traduzem conformações de amizade característicos da eúnoia pelo gesto solidário de simpatia que se infiltra no discurso como um caminho para mover o auditório.

Os diversos enfoques sobre a noção de ethos mostram que o fenômeno não é tratado de forma padronizada, ao contrário. Nesse sentido, ainda segundo Ferreira (2019, p. 14), o conceito de ethos liga-se à vocalidade, pois é por meio da fala que nos expressamos formando uma certa imagem de nosso caráter "É a vocalidade que carrega elementos ligados à personalidade, ao caráter, aos traços comportamentais e a todos os elementos que se aglutinam no ato retórico como maneira de sentir e apresentar signos corporais, gestos e maneiras de falar". Dessa forma, por meio da vocalidade, o orador pode criar uma imagem agradável de si para persuadir o auditório.

A noção de ethos fundamentada na Retórica de Aristóteles deu margem a outras abordagens para o fenômeno. O estudo teórico sobre o ethos é também abordado e ampliado na área da Análise do Discurso. Maingueneau (2008, p. 13), um dos pioneiros do tema nessa abordagem teórica, resgata a concepção tratada pelo filósofo na antiguidade, quando considera que "a prova pelo ethos consiste em causar boa impressão pela forma como se constrói o discurso, a dar uma imagem de si capaz de convencer o auditório, ganhando sua confiança". Do excerto, é possível compreender que é por meio do discurso que o orador transmite uma imagem agradável de si, capaz de persuadir o auditório conquistando a adesão do público a quem se dirige.

Maingueneau (2008, p. 15), no entanto, traz um novo olhar sobre esse conceito ao observar que é possível construir imagens do outro 
antes de um enunciado, isso se verifica em: "não se pode ignorar que o público constrói também representações do ethos do enunciador antes mesmo que ele fale". Essas representações são criadas a partir dos efeitos de sentidos no discurso e do conhecimento prévio que o público já obtém do enunciador. Após o conhecimento do ethos pré-discursivo do locutor, os interlocutores terão a capacidade de confirmar se por meio do discurso tais imagens preconcebidas associadas ao orador conferem ou não.

O ethos pré-discursivo é concebido por estereótipos, ou seja, uma imagem pré-construída, que diz respeito ao caráter, bem como aos julgamentos feitos pela sociedade em função do que se acredita pelo senso comum, sem conhecimento profundo, sobre algo ou alguém. É o que podemos verificar em:

o destinatário constrói, de maneira mais ou menos fluída, mais ou menos consciente, a figura desse fiador apoiando-se em um conjunto difuso de representações sociais estereotipadas, valorizadas ou desvalorizadas, que a enunciação contribui para reforçar ou transformar (MAINGUENEAU, 2020, p. 14)

Com base no exposto sobre a noção de ethos, em nossas análises serão considerados especificamente os pressupostos de Aristóteles (2015), Ferreira $(2010 ; 2015)$, Fiorin (2015) e Maingueneau (2008, 2020). Ainda é preciso acrescentar que o ethos ou as imagens do protagonista da série são depreendidos do discurso (logos), que aqui compreende tanto os diálogos transcritos das cenas (considerando-se tom) quanto os stills das cenas captadas, os quais são capazes de mostrar a expressão facial e gestualidade (cf. TRINGALI, 1988 ; MAINGUENEAU, 2020).

Como o foco deste artigo é analisar a mudança da construção do ethos de Naruto, entendemos ser relevante, antes da análise, fazermos uma breve contextualização da série a fim de que se possa compreender a trajetória da vida do personagem principal e, consequentemente, como o ethos do personagem é construído e reconstruído. 


\section{NARUTO, O ANIME}

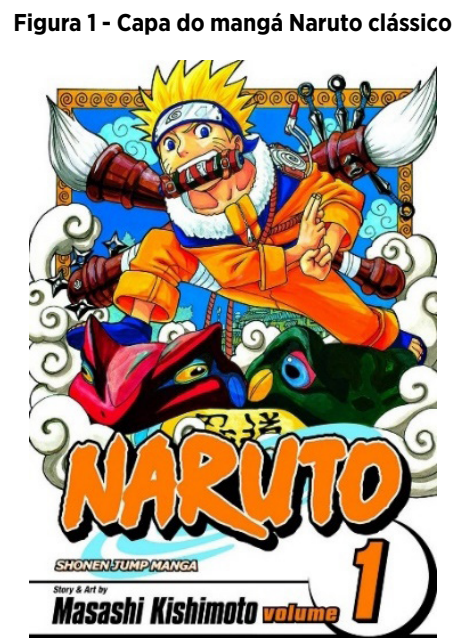

Fonte: AMAZON (2020)

Naruto é um mangá escrito por Masashi Kishimoto em 1999 e publicado na revista Weekly Sh区nen Jump (cf. SOUZA, 2018). Anos depois, foi adaptado em anime, isto é, em desenho animado. Dividida em duas partes, a série japonesa possui ao todo 720 episódios, com duração de vinte minutos cada. A primeira parte, "Naruto Clássico", apresenta 220 episódios e a segunda, denominada "Naruto Shippuden", 500. Segundo registra Paris (2019), tanto o mangá, quanto o anime chegaram ao Brasil em 2007, a obra escrita foi publicada pela editora Panini Comics, responsável por sua circulação no país.

Pereira (2011), que investiga aspectos de construção da subjetividade e culturais de um "animencontro" (termo referente ao encontro de fãs de animes), versa sobre a relevância da saga Naruto representada não somente pelos cosplays dos fãs que se caracterizam de acordo com seu personagem favorito da animação, mas também pelos diversos produtos criados a partir do desenho: "A saga também gerou filmes, jogos eletrônicos e jogos de cartas colecionáveis de grande sucesso, o que demonstra sua penetração e forte aceitação pelo público" (PEREIRA, 2011, p. 115).

A trama tornou-se um sucesso, conquistando a atenção da audiência, seja pela série em si e sua animação, seja pela identificação com o personagem e sua história de vida. Sua relevância foi tamanha que, 
em 2018, a série ganhou continuação, em mangá e anime, com o filho de Naruto, Boruto Uzumaki, em "Boruto: Naruto Next Generations".

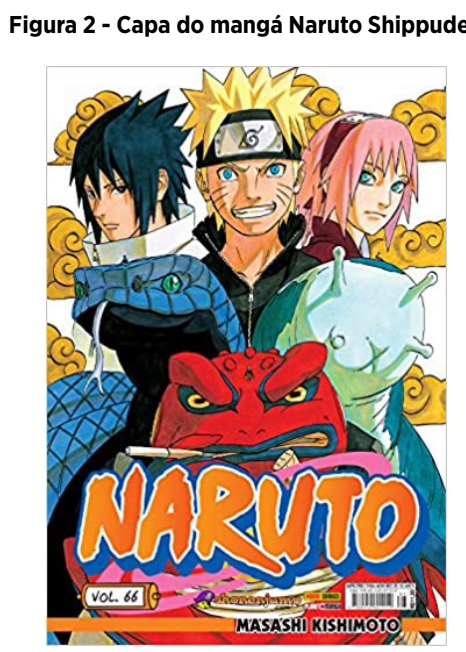

Fonte: AMAZON (2020)

Noboa (2019), ao analisar a influência do anime Naruto, sobretudo no que tange à sua propagação nas redes sociais, salienta que a série tem atingido muitos países em quase todos os continentes. A autora afirma que "há pessoas que experimentam tanto o fanatismo por esse anime que mudam muitas atividades de sua vida cotidiana para vê-lo, ou, por vez, adquirem condutas similares às do personagem principal" (2019, p. 4, tradução nossa) ${ }^{1}$. Por meio dessa consideração, observamos não só a relevância do anime, mas também o seu poder de persuasão.

Com relação à trama, a história dos ninjas acaba se consolidando antes da produção em animação. O mundo shinobi teve origem com uma "deusa" chamada Kaguya, que veio do céu para a Terra. A princípio, seus objetivos na Terra eram nobres, proteger a Árvore divina, que a cada milênio produzia um fruto que concedia poderes sobrenaturais e paz no mundo. Essa deusa celestial se apaixona por um humano e fica grávida de gêmeos, Hagoromo e Hamura. Temida por seu poder, o pai de seus próprios filhos trai a sua confiança, comandando um exército para matála. A fim de proteger os bebês que carregava no ventre, Kaguya come o

1 No original: "Hay personas que experimentan tanto fanatismo por este anime que cambian muchas actividades de su vida cotidiana por verlo, o, a su vez, adquieren conductas similares al personaje principal". 
fruto da Árvore, dando origem ao chakra e pondo um fim àquele ataque com o Tsukuyomi infinito.

Ressentida pela traição, Kaguya corta seus laços com os humanos. Com o passar dos anos, Hagoromo e Hamura cresceram. Compreendendo a gravidade do que sua mãe estava fazendo com os humanos, prendendoos sob a Árvore para sugar a energia vital das pessoas, seus próprios filhos encontraram uma maneira de pará-la. Assim, após uma intensa batalha, os dois conseguem aprisionar Kaguya na lua. Hamura vai para lua, junto de sua mãe, enquanto Hagoromo permanece na terra para dar continuidade à sua jornada, restaurando a destruição causada pela luta.

O conceito de ninja nasce a partir do Ninshu (crença ninja), criado por Hagoromo, no qual conectava todos os seres a partir do chakra que compartilhava com as pessoas. Esse chakra é a energia elementar, a fonte da força física e espiritual de um ninja. É também por meio dessa força que os shinobs desenvolvem seu poder e habilidades. Assim, gerações se passaram, até o nascimento de Naruto, personagem que dá o nome à série.

No geral, a série se passa em Konoha (aldeia da Folha) e é caracterizada pela ação, pelo humor bem como pelo companheirismo entre os personagens. A primeira parte da história acompanha a trajetória da pré-adolescência de Naruto Uzumaki, órfão desde bebê. Enquanto criança, Naruto cometia diversas travessuras para chamar a atenção. Seu grande desejo era conquistar o respeito e o reconhecimento de todos e se tornar um grande Hokage, título referente ao ninja líder de sua aldeia.

O primeiro episódio inicia-se com o relato sobre a calamidade ocorrida na aldeia, quando uma fera, a Raposa de nove caudas, chamada Kurama, atacou a vila destruindo-a quase por completo, causando a morte de incontáveis cidadãos. Foi nesse ataque que Naruto nasceu e seus pais, Kushina e Minato (o quarto Hokage) morreram. Para proteger a todos, antes de sua morte, Minato selou a fera dentro de seu filho, aprisionando-a com uma marca que a impede de sair. Pelo fato de Naruto possuir dentro de si o poder da Besta de caudas, a que causou uma grande devastação na Folha, as pessoas tinham medo dele e não o respeitavam. Por ser órfão, teve que crescer sozinho e "descobrir o mundo" à sua maneira. Além disso, Naruto era o pior estudante de sua classe, já que tirava sempre notas baixas, o que contribuía ainda mais para os diversos insultos e humilhações por parte dos outros alunos. Hinata, uma colega de turma, era a única que o admirava e que não o desrespeitava. 
Ainda nessa primeira parte, a aventura mostra os laços de amizade que Naruto estabelece com os colegas de sua turma e com seus professores, em especial o da academia, Iruka sensei, o primeiro a reconhecê-lo como alguém importante e não como a Raposa, um monstro feroz. Ao se formar na academia e receber a bandana que o identifica como ninja da Folha, Naruto passa a fazer parte de uma equipe de três, juntamente com Sakura e Sasuke Uchiha, integrantes do time sete, liderado por seu novo professor, Kakashi. Nessa equipe, o protagonista desenvolve uma relação mútua com seu time, principalmente com Sasuke, seu amigo e rival.

Sasuke tinha uma ambição: tornar-se forte para matar seu irmão, Itachi Uchiha, responsável por assassinar a sangue frio todos os Uchihas. Para atingir tal propósito, ele foge da vila, tornando-se um renegado, e se alia a um antigo vilão, Orochimaro, em busca de poder. Inconformado com o ocorrido, Naruto não desiste de seu amigo, fazendo de tudo para trazê-lo de volta para casa. Essa primeira parte termina quando o protagonista precisa fazer com seu novo mestre, Jiraya, com quem desenvolve um afeto mútuo, para treinar e ficar forte o suficiente para se defender de um recente grupo de vilões que surge, denominado Akatsuki.

A segunda parte da série, nomeada Naruto Shippuden, começa com a volta de Naruto já adolescente à vila. Com a Akatsuki na ativa, Naruto e vários outros ninjas se preparam para a batalha, empenhandose em evitar que este grupo atinja seus objetivos maléficos de capturar todas as Bijuus (as Bestas de caudas), no intuito de obter o poder absoluto e ter o controle sobre todos, juntamente com a missão de resgatar Sasuke de volta para vila.

Nessa sessão, um antigo ninja poderoso, Madara Uchiha, é ressuscitado, dando início à quarta grande guerra. Em estado de emergência, com o mundo correndo perigo, shinobis de todas as nações se aliam para deter o inimigo. Mas os planos desse impetuoso vilão não ocorrem como esperado. Tudo não passou de uma estratégia forjada pelo Zetsu preto, criação de Kaguya, a progenitora do chakra que deu origem ao mundo ninja, de retornar a vida.

Depois de sua longa jornada como renegado da vila da Folha, Sasuke retorna para ajudar no campo de guerra. Então, após uma árdua batalha, Naruto e Sasuke conseguem derrotar Kaguya, selando-a novamente na lua, pondo um fim à guerra. Mas o rancor de Sasuke contra a vila, mais precisamente contra Naruto, continuava. Em seguida, eles vão para o Vale do Fim acertar as contas. A batalha final entre Sasuke e Naruto se 
dá devido às discrepâncias na forma de pensar dos personagens sobre o que é ser um verdadeiro Hokage.

Planejando se tornar o líder da aldeia e assumir o controle de tudo e de todos, Sasuke pretendia eliminar as Bijuus, bem como os atuais Kages das outras vilas, em oposição a isso, Naruto parte para luta a fim de impedi-lo. A briga resulta na derrota de Sasuke e no seu reconhecimento sobre Naruto, assim, ambos reatam seus laços de amizade. Naruto sempre considerou Sasuke como um irmão que nunca teve, pois se identificava com o sofrimento que ele havia passado. A série termina com o casamento de Naruto com Hinata, a qual o admirava desde criança, seja por sua bravura, seja por nunca desistir de seus sonhos.

\section{OS ETHÉ DE NARUTO EM ANÁLISE: DA CONSTRUÇÃO À RECON- STRUÇÃO DE SI}

Nesta parte do texto, selecionamos aleatoriamente sete cenas de episódios da série, a partir das quais buscamos mostrar não só como a imagem do protagonista é construída, mas também como Naruto reconstrói ethé de si especificamente a partir das características integrantes ao ethos, quais sejam: phrónesis, areté e eúnoia. Passemos, então, à análise propriamente dita.

\section{a) Cena 1}

Figura 3- Reações das pessoas ao verem Naruto

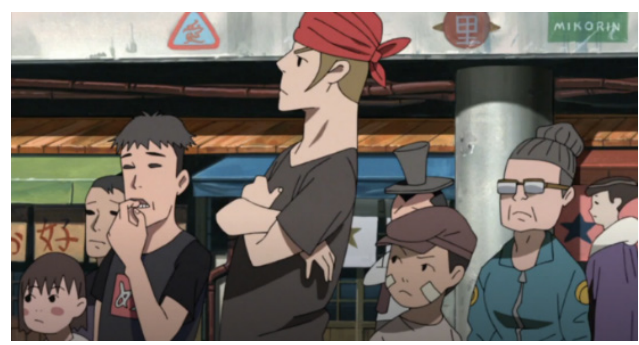

Fonte: ANIMES ONLINES (2020, EP. 480) 


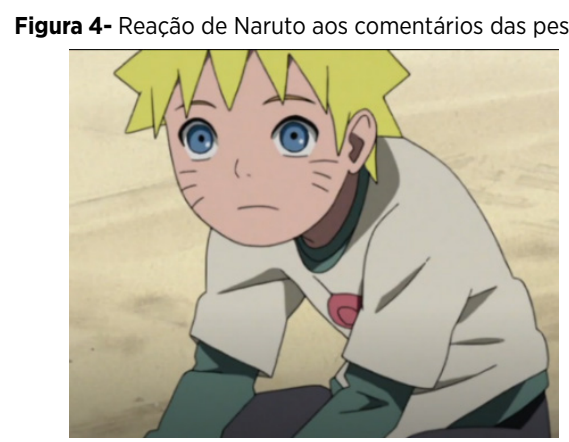

Fonte: ANIMES ONLINES, 2020, EP. 480)

\section{Diálogo 1}

Personagem não identificado: ouvi dizer que é verdade

Personagem não identificado: é aquele menino né?

Personagem não identificado: vejam... não é aquele ali? ele me assusta

Personagem não identificado: Ei... não brinque com ele...você não sabe o que ele fará

A primeira cena a ser analisada consta do episódio 480, de Naruto Shippuden, denominado "Naruto - Hinata", e dura em torno de 26 segundos (2'39" a 3'06"). Por se tratar de um episódio flashback, que apresenta Naruto ainda criança, é possível observar uma primeira imagem do personagem. Como se verifica pela Figura 3 da cena em questão e pelo diálogo transcrito, ao avistarem Naruto, os cidadãos da vila comentam entre si não apenas sobre como o veem, mas, também, o que sentem em sua presença. Desse modo, as imagens do protagonista são mostradas pelos outros de forma negativa, como temível, assustador, nocivo ("Ele me assusta") e imprevisível ("não brinque com ele...você não sabe o que ele fará").

No que concerne às características do ethos, os que constroem as imagens de Naruto não apresentam um ethos de phrónesis nem de eúnoia, visto que não são razoáveis, tampouco solidários e amigáveis. Valem-se, no entanto, da areté para a formulação de tais imagens, pois se apresentam como sinceros e desbocados ("ele me assusta") e ("não brinque com ele...você não sabe o que ele fará). A qualidade conhecida como areté, segundo Fiorin (2015, p. 71), revela a virtuosidade de um orador, seu ato corajoso, bem como a sinceridade ao proferir seu discurso: "a areté, que denota a virtude, mas virtude tomada no seu sentido 
primeiro de 'qualidades distintivas do homem', portanto a coragem, a justiça, a sinceridade; nesse caso, o orador apresenta-se como alguém simples e sincero, franco ao expor seu ponto de vista".

Com relação às falas dos personagens da cena, evidencia-se o que Maingueneau (2008) denomina como ethos pré-discursivo uma imagem construída exterior ao discurso. Desse modo, a partir de representações sobre o protagonista, efeitos de sentidos são criados por parte dos interlocutores. Do diálogo, notamos que os ethé de "temível", "assustador", "nocivo" e "imprevisível" são gerados por interpretações de imagens preconcebidas, conforme se nota a partir dos enunciados "é aquele menino né" e "não é aquele ali". As imagens negativas do protagonista, pré-estabelecidas, decorrem do que aconteceu quando Naruto nasceu, isto é, quando a vila foi atacada pela fera de Nove caudas e selada dentro do referido personagem.

Da Figura 3, notamos os gestos e expressões dos personagens, recursos retóricos relevantes para construções dos ethé. Sobre os efeitos da corporalidade para a formação de imagens, Declerq (1942, p. 48, apud MAINGUENEAU, 2020, p. 10) afirma:

\footnotetext{
Tom de voz, ritmo da fala, seleção vocabular e argumentos, gesto, expressão facial, olhar, postura, figurino, etc. são igualmente signos elocutórios e oratórios indumentários e simbólicos, pelos quais o orador da de si mesmo uma imagem psicológica e sociológica.
}

No que diz respeito ao tom de voz, o diálogo não revela alterações, como se observa pela transcrição (dados que seriam mostrados pelas letras maiúsculas). Quanto ao ritmo das falas, notamos pequenas pausas (as quais são representadas na transcrição das cenas pelas reticências): "vejam... não é aquele ali", "Ei... não brinque com ele...você não sabe o que ele fará". As pausas, nesse caso, sugerem certo temor quando se referem a Naruto. Outros recursos observados no still da cena que corresponde à Figura 3 referem-se às expressões faciais e aos gestos sobrancelha erguida, dedo na boca, braços cruzados - o que indicam um certo com a presença de Naruto. Esses expedientes retóricos corroboram para a construção dos ethé identificados do protagonista. 
b) Cenas 2 e 3

Figura 5 - Naruto foge após pichar os monumentos

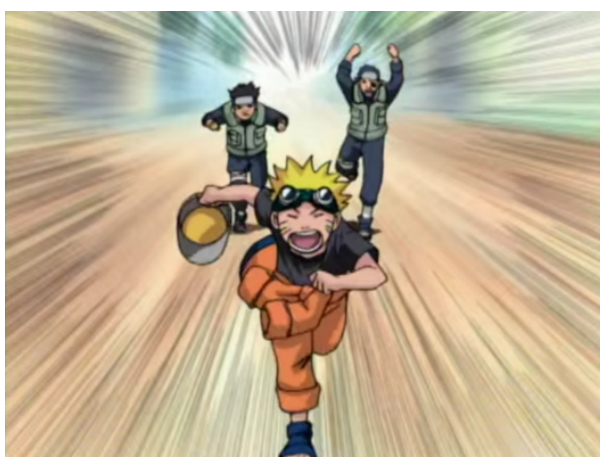

Fonte: NETFLIX, (2020, TEMP. 1, EP. 1)

Figura 6 - resultado do pichamento

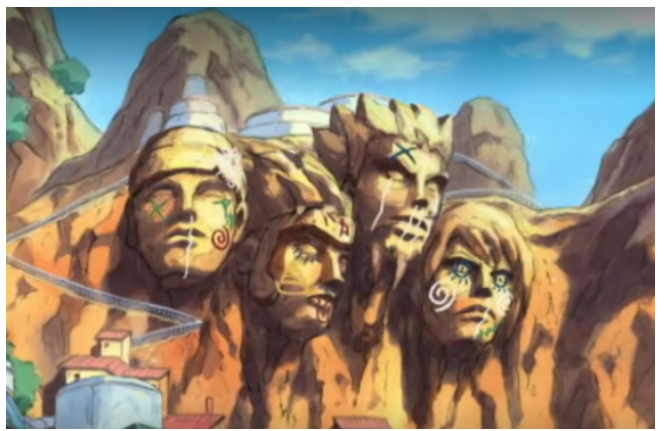

Fonte: NETFLIX (2020, TEMP. 1, EP. 1)

Diálogo 2

Naruto: ((RISOS))

Personagem 1, à direita: NARUTO VOLTA AQUI...QUANDO EU PUSER MINHAS MÃOS EM VOCÊ

Personagem 2, à esquerda: VOCÊ PASSOU DOS LIMITES DESSA VEZ NARUTO

A cena em questão encontra-se no início do episódio 1 da primeira temporada de Naruto clássico, intitulado "Enter: Naruto Uzumaki" e 
dura 12 segundos (1'03" a $\left.1^{\prime} 15^{\prime \prime}\right)$. Para chamar a atenção, muitas vezes Naruto fazia brincadeiras inapropriadas, como, por exemplo, pichar monumentos considerados importantes, caso dos rostos dos antigos Hokages, grandes heróis que deram suas vidas em prol da proteção da vila, gravados no pico de uma montanha em forma de homenagem.

Dois personagens perseguem Naruto para que ele responda por suas ações. Tanto os dois personagens na cena quanto Naruto contribuem para a constituição de sua imagem. O protagonista desvela para si o ethos de malcomportado, pichando os rostos esculpidos dos antigos líderes da vila, como apresentado na Figura (6). Essa imagem é reforçada pelos interlocutores a partir do enunciado "VOCÊ PASSOU DOS LIMITES", em que a expressão assume um valor semântico pejorativo e remete às atitudes de Naruto como inadequadas, dado que desvela para ele um ethos negativo (o de malcomportado). Não há evidências de construções da imagem do protagonista segundo as três disposições do ethos. Nas falas transcritas, os interlocutores não se apresentam como prudentes (phrónesis) nem como virtuosos (areté) ou solidários (eúnoia).

Dos stills das cenas referentes às figuras (5) e (6), é possível depreender alguns aspectos da corporalidade que corroboram para o ethos identificado. Sobre isso, Maingueneau (2020, p. 14) ressalta que "'corporalidade' [...] está associada a uma compleição física e uma maneira de se vestir, a um modo de se mover no espaço social, a um comportamento". Nesse sentido, constrói-se uma representação da imagem do enunciador por sua maneira de agir.

Conforme se verifica na Figura (5), Naruto corre e sorri com a boca aberta, como quem foge após ter feito algo inapropriado. Na transcrição do diálogo, observamos na fala do protagonista um tom enfático - que pode ser verificado pelas letras grafadas em caixa alta, ((RISOS)), o que mostra estar satirizando a situação. Tal atitude revela sua maneira de se impor no discurso, "um modo de se mover no espaço social". Em seguida, observamos dois personagens correndo atrás de Naruto com os braços levantados, o que sugere estarem bravos com a situação, levandonos a confirmar o mal comportamento do protagonista.

No still da cena da Figura (6), notamos marcações de tinta por toda parte nos rostos das estátuas de pedras, tinta escorrendo do nariz, dos olhos. Por se tratar de um monumento considerado sagrado pelos aldeões da Folha, esse comportamento do protagonista para chamar a atenção causou um impacto negativo, que possibilita uma "corporalidade" não aceita pelo outro, desvelando uma imagem de si de malcomportado. 


\section{c) Cena 4}

Figura 7 - Naruto fala sobre sua motivação em virar Hokage

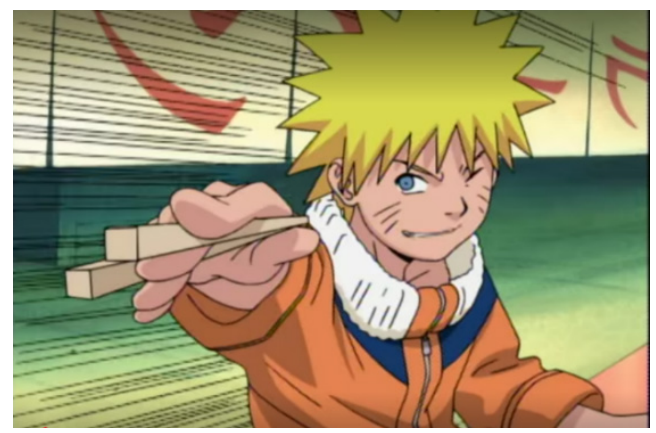

Fonte: NETFLIX (2020, TEMP. 1, EP. 1)

\section{Diálogo 3}

Iruka: Naruto?

Naruto: ((hm::))

Iruka: por que fez aquilo nos rostos dos Hokages...sabe muito bem quem foram eles não sabe?

Naruto: CLA::ro que eu sei...TODO mundo sabe eles foram os maiores shinobi de sua época os maiores de todos invencíveis campeões ninjas...e o quarto Hokage foi quem salvou a aldeia da Raposa de nove caudas ELE FOI O MAIS INCRÍVEL

Iruka: então por quê?

Naruto: PORQUE eu vou ser maiOR do que TOdos eles...EU... NARUTO...O PRÓXIMO HOKA::GE UMA LENDA NINJA as pessoas vão parar de me desprezar e olhar pra mim...TO CERTO

A presente cena dura 46 segundos $\left(4^{\prime} 44^{\prime \prime}\right.$ a $\left.5^{\prime} 30^{\prime \prime}\right)$ e ocorre na lanchonete favorita do protagonista, na qual Iruka o convida para comer lámem e conversar sobre os motivos que levaram Naruto a pichar os rostos das esculturas de pedras dos antigos Hohages. Nessa passagem, percebemos uma primeira reconstrução do ethos do protagonista a partir de seu discurso. A transcrição da cena permite observar a construção de alguém determinado em se tornar um líder respeitado ("eu vou ser maiOR do que TOdos eles"). No que concerne às características do ethos vistas em Aristóteles (2015), Fiorin (2015) e Ferreira (2019), nota-se que 
o protagonista manifesta um ethos de areté, uma vez que demonstra em seu discurso ser franco, sincero e temerário ao expor suas convicções, como se verifica em "PORQUE eu vou ser maiOR do que TOdos eles... EU...NARUTO...O PRÓXIMO HOKA::GE UMA LENDA NINJA as pessoas vão parar de me desprezar e olhar pra mim...TO CERTO".

Outros recursos retóricos que auxiliam a identificação do ethos de determinado de Naruto são os efeitos de voz e a gestualidade, sobre os quais Tringali (1988, p. 99) afirma: "a expressão oral, o recitativo, a saber, o ritmo, a melodia, a intensidade, pausa... A voz que se eleva ou abaixa, que se apressa ou retarda... acrescenta novos significados à pronunciação". Os efeitos de voz observados são demarcados pela entonação enfática da fala do personagem (representadas, na transcrição, pelas letras grafadas em maiúsculas) que expressam um volume mais alto e enfatizado ("PORQUE eu vou ser maiOR do que TOdos"; "EU... NARUTO...O PRÓXIMO HOKA::GE UMA LENDA NINJA"; "TO (ERTO"), o que demonstra convicção no que diz.

Concernente ao still da cena que se refere à Figura (7), percebemos seu semblante de autoconfiança (visto por meio da piscada com um olho e o dedo apontado para frente) - para finalizar seu discurso de que se tornaria um grande líder respeitado, ele afirma com um tom enfático: "TO CERTO". Tanto o semblante quanto a intensidade com que enuncia são elementos igualmente significativos que ajudam a desvelar sua imagem de determinado.

\section{d) Cena 5}

Figura 8 - Naruto não se dá por vencido

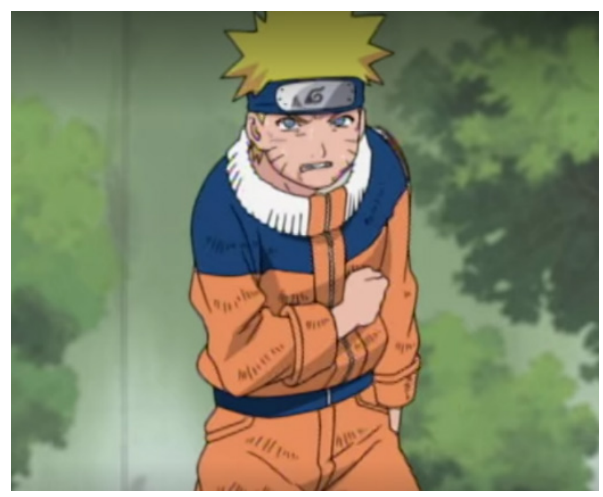

Fonte: NETFLIX (2020, TEMP. 3, EP. 10) 


\section{Dialogo 4}

Neji: está no seu destino perder pra mim...pode acreditar

Naruto: AH:: É::... NÓS NÃO SABEREMOS DISSO ATÉ QUE VOCÊ ME DERROTE...tá legal...seu pai foi morto há muito tempo atrás... e eu sei que não foi justo e talvez você esteja chateado por isso EU ENTENDO MAS ISSO NÃO TEM NADA A VER COM DESTINO SE ACHA QUE EU ENGULO ESSA ESTÁ ERRADO

Neji: você jamais entenderá

Naruto: AH:::

Neji: EXAMINADOR...a luta acabou...hum...você é um fracassado ((abertura))

Naruto: espera...não vai embora...eu ainda...não acabei...eu não... desisto...eu jamais voltarei atrás na minha palavra...PORQUE ESSA É MINHA CONDUTA NINJA

A cena em foco encontra-se no episódio 10 da terceira temporada, intitulado "O verdadeiro poder do perdedor", com duração de 1 minuto e 34 segundos (2'09" a $\left.3^{\prime} 45^{\prime \prime}\right)$. Ela ocorre no exame Chunin, uma competição que, segundo os estudos de Paris (2019, p. 62), "é quando os melhores genins da Aldeia da Folha e outras Aldeias vizinhas se juntam para prestar um exame para selecionar ninjas para tornarem-se Chunin, com o propósito de melhorar as relações entre os aliados e aumentar o nível ninja". Nesse torneio, o oponente de Naruto é Neji, um jovem pertencente de um poderoso clã da vila, os Hyuugas.

Neji tinha fortes crenças de que todos nascem com um destino traçado e que deveriam segui-lo obedientemente. Ao derrubar Naruto diversas vezes, quase ganhando a luta, o personagem constrói um ethos negativo de Naruto como fracassado ("você é um fracassado"). As convicções de Neji tendem a mostrar o ethos de Naruto como de perdedor, fracassado, pois era o que estava predestinado ao protagonista ("está no seu destino perder pra mim").

Das qualidades do ethos, o referido personagem constrói a imagem de Naruto segundo a areté, visto que se mostra sincero e desbocado ("está no seu destino perder pra mim...pode acreditar" e "você é um fracassado"). Nesse caso, conforme Fiorin (2015, p. 71) destaca, "o orador apresenta-se como alguém simples e sincero, franco ao expor seu ponto de vista".

Da cena, observamos que o protagonista reconstrói sua imagem por meio da eúnoia. Para Fiorin (2015, p. 71), o orador "que usa a eúnoia 
apresenta-se como alguém solidário com seu enunciatário, como um igual". Em "... tá legal...seu pai foi morto a muito tempo a trás... e eu sei que não foi justo e talvez você esteja chateado por isso EU ENTENDO...", o protagonista apresenta ser simpático e solidário com seu oponente.

Em seu discurso, Naruto reconstrói para si um ethos de persistente. O que pode ser visto a partir do enunciado "eu ainda...não acabei...eu não...desisto". Mesmo fraco e à beira de perder a competição, ele não se dá por vencido. Notamos mais uma vez que o protagonista põe em evidência a areté, apresentando um caráter autoconfiante, temerário e corajoso ("eu jamais voltarei atrás na minha palavra...PORQUE ESSA É MINHA CONDUTA NINJA").

Referente à intensidade e ao volume da voz, recursos retóricos que auxiliam na construção do ethos, notamos que o protagonista apresenta um tom enfático (expresso pelas letras maiúsculas): "AH:: É::... NÓS NÃO SABEREMOS DISSO ATÉ QUE VOCÊ ME DERROTE", "EU ENTENDO MAS ISSO NÃO TEM NADA A VER COM DESTINO SE ACHA QUE EU ENGULO ESSA ESTÁ ERRADO", "PORQUE ESSA É MINHA CONDUTA NINJA". O tom expresso demonstra convicção, ou seja, segurança ao dizer.

e) Cena 6

Figura 9 - Naruto confronta Pain

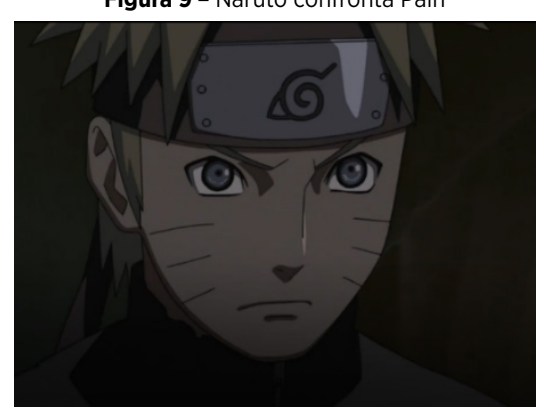

Fonte: ANIMES ONLINE (2020, EP. 174)

Dialogo 5

Naruto: e o nome do herói desse livro...É NARUTO...meu nome...É UM LEMBRETE IMPORTANTE DO SABIO TARADO...EU NÃO POSSO DESISTIR E SUJAR O LEGADO DO MEU MESTRE...EU VOU SER 


\section{HOKAGE...E VOU LEVAR PAZ PARA CHUVA...POR FAVOR ACREDITE EM MIM}

Nagato: como?...como você pode dizer que nunca vai mudar?...que você não vai mudar não importa a dor pela qual passe VOCÊ CONSEGUE CONTINUAR ACREDITANDO EM SI MESMO...VOCÊ TEM FÉ...EM SI MESMO?

Naruto: eu também...passei por dor ((flashback)) e tem muita dor... dentro de mim também...mas não sabemos que tipo de dor virá atrás de nós...mas...se eu parar por causa disso...se o herói mudar...vai virar outra história...vai virar uma história diferente da que meu mestre deixou...ENTÃO NÃO VAI SER O NARUTO...eu não consigo escrever como meu mestre...por isso...a sequência tem que vir da minha vida... NÃO IMPORTA O QUANTO A DOR SEJA GRANDE eu vou continuar andando...ESSE É QUEM O NARUTO É

A presente cena consta do episódio 174 de Naruto Shippuden intitulado "A história de Uzumaki Naruto", com duração de 3 minutos e 30 segundos (14'07" a 17'37"). Nessa cena, a aldeia da Folha é invadida por Pain (os seis caminhos da dor), um pseudônimo criado por Nagato da vila da Chuva e discípulo de Jiraya, assim como Naruto. Nagato, um dos membros da Akatsuki, utiliza receptores de chakra perfurados no corpo de cadáveres para controlar esses pseudônimos. Seguindo seus ideais de que para haver paz o mundo precisaria conhecer a dor, ele causa uma grande devastação na vila da Folha em busca de Naruto. Após derrotar Pain em uma intensa batalha, Naruto se encontra frente a frente com Nagato para dialogar sobre suas perspectivas de paz para Terra. No diálogo, nota-se a construção de ethé positivos que o protagonista revela de si.

De início, no diálogo transcrito, notamos uma primeira construção positiva do ethos do protagonista pelo outro. Em seu livro, Jiraya (Sábio Tarado) desvela a imagem de Naruto como herói ("e o nome do herói desse livro...É NARUTO"). Por meio de seu discurso, Naruto constrói para si ethé de persistente e determinado ("EU NÃO POSSO DESISTIR"; "EU VOU SER HOKAGE"). No que tange às disposições do ethos, o herói se vale da areté para construção de sua imagem, pois mostra ser franco, sincero e confiante ao afirmar trazer a paz até mesmo para outras vilas ("E VOU LEVAR PAZ PARA CHUVA...POR FAVOR ACREDITE EM MIM").

Após ser questionado por Nagato se ele de fato teria a confiança suficiente de acreditar em si mesmo, Naruto desvela aspectos da eúnoia, 
mostrando-se solidário e altruísta ao se identificar com a dor de seu auditório ("eu também...passei por dor [...] e tem muita dor...dentro de mim também"), desse modo estabelece um vínculo de proximidade com o outro. O protagonista ainda admite que se deixar levar pelos sentimentos negativos não mostraria quem ele realmente é, pois prejudicaria o legado que havia sido confiado a ele pelo mestre que tanto o preza. Nesse sentido, mais uma vez Naruto se mostra determinado em nunca desistir ("NÃO IMPORTA O QUANTO A DOR SEJA GRANDE eu vou continuar andando"), desvelando novamente um ethos de areté, isto é, de virtuoso ("ESSE É QUEM O NARUTO É").

Outro recurso retórico a ser destacado é o efeito de voz. O tom enfático, expresso com as letras maiúsculas na transcrição do diálogo, evidencia o que Tringali (1988, p. 99) afirma: "a voz que se eleva ou abaixa, que se apressa ou retarda... acrescenta novos significados à pronunciação". Observa-se, uma vez mais, que o tom elevado do protagonista expressa sua convicção ("É NARUTO...É UM LEMBRETE IMPORTANTE DO SABIO TARADO...EU NÃO POSSO DESISTIR E SUJAR O LEGADO DO MEU MESTRE...EU VOU SER HOKAGE...E VOU LEVAR PAZ PARA CHUVA...POR FAVOR ACREDITE EM MIM"; "ENTÃO NÃO VAI SER O NARUTO"; "NÃO IMPORTA O QUANTO A DOR SEJA GRANDE" e "ESSE É QUEM O NARUTO É"), o que corrobora a construção dos ethé que Naruto desvela de si.

Do still da cena que se refere à Figura (9), notamos o semblante do protagonista que denota seriedade (pelo olhar sério e sobrancelhas franzidas), o qual dá a impressão de convicção em seu discurso. Segundo Maingueneau (2020, p. 10), os efeitos de corporalidade são recursos significativos na construção de imagens: “(...) expressão facial, olhar, postura, figurino, etc. são igualmente signos elocutórios e oratórios indumentários e simbólicos, pelos quais o orador da de si mesmo uma imagem psicológica e sociológica". 


\section{f) Cena 7}

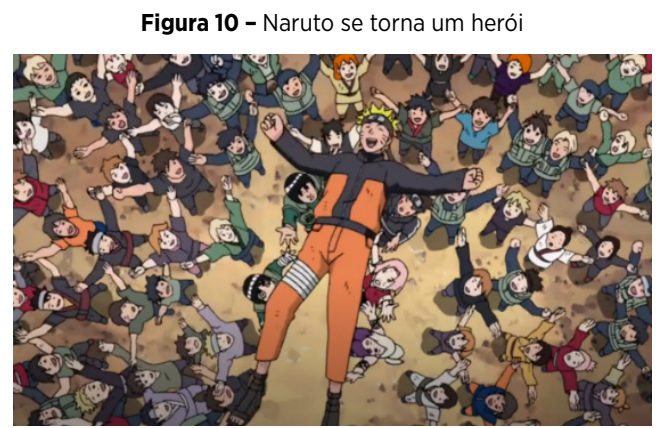

Fonte: ANIMES ONLINE (2020, EP. 175)

\section{Diálogo 6}

Ebisu: Naruto é incrível...né?...primeiro todos pensaram que ele era um problemão incluindo eu...nós temíamos o destino dele então o mantínhamos distante e não nos importávamos com ele ((flashback)) mas ele nunca desistiu e nunca mudou seu jeito ninja e devagar mas sem parar tivemos que reconhecê-lo ((flashback)) hoje todos confiam implicitamente no Naruto eles se preocupam e tem esperanças além de rezar por ele...ele mudou muito o que muitas pessoas pensavam

Iruka: é porque ele deu o seu melhor

A cena apresentada encontra-se no episódio 175 de Naruto Shippuden e dura 4 minutos e 20 segundos (15'00" a 19'20"). Após ter convencido Nagato a mudar de atitude e desistir de atacar a vila, Naruto volta para Folha e é abraçado pela multidão que o aguardava ansiosa por sua chegada.

Do diálogo transcrito entre dois professores da academia ninja, depreendemos reconstruções de imagens engendradas na enunciação por parte do outro. Ebisu, assim como muitos de sua aldeia, tinha uma imagem negativa de Naruto, o qual era visto como um problema ("primeiro todos pensaram que ele era um problemão incluindo eu"), além de insignificante, sem importância ("nós temíamos o destino dele então o mantínhamos distante e não nos importávamos com ele"). Em seu próprio discurso, Ebisu recria essa imagem postergada do protagonista.

À medida que Naruto foi crescendo, demonstrando um caráter de bravura e determinação, por meio da areté, que parte da virtuosidade, 
da excelência, Ebisu denota o ethos de Naruto como admirável ("Naruto é incrível...né"). O mesmo atribui uma imagem ao personagem de persistente e respeitável, como se observa por meio dos enunciados: "mas ele nunca desistiu e nunca mudou seu jeito ninja" e "mas sem parar tivemos que reconhecê-lo". Com base nessas explanações, Naruto atinge um de seus sonhos de ser conhecido e respeitado pelas pessoas.

Além do exposto, verificamos também ethé de confiável ("hoje todos confiam implicitamente no Naruto") e querido ("eles se preocupam e tem esperanças além de rezar por ele"), ou seja, o oposto do que demonstravam observar em Naruto.

No still da cena que se refere à Figura (10), observamos que as pessoas mostram Naruto como querido e respeitado, dado depreendido pelo fato de o protagonista ser jogado para o alto pela multidão em um gesto carinhoso por ele ter salvado a vila toda. Nesse caso, verifica-se a manifestação de um ethos de eúnoia, o qual, segundo Fiorin (2015, p. 71), apresenta "alguém solidário com seu enunciatário, como um igual, cheio de benevolência e de benquerença".

É então, a partir dessa cena, que Naruto reconstrói seu ethos definitivamente. O ethos reconstruído é a prova retórica que persuade o auditório. Ferreira (2019, p. 16) afirma: "o homem virtuoso cumpre o ato determinado, conhece o que faz e o executa voluntariamente como resultado de uma disposição permanente." Sua persistência e determinação foram essenciais para o processo da reconstrução de sua imagem.

\section{CONSIDERAÇÕES FINAIS}

Com base nas análises das cenas captadas, notamos que, no início da série, Naruto é construído de forma negativa pelos outros, a saber, temível, assustador, nocivo, imprevisível, malcomportado, fracassado, insignificante. Os que constroem tais imagens do protagonista apresentam em seu discurso as características da areté, já que se mostram desbocados, sinceros e francos.

Mas isso muda. E é essa mudança que buscamos retratar neste artigo. As análises mostram que tal reconstrução do ethos parte não só do próprio Naruto, mas também dos outros. Dentre as imagens que o protagonista desvela de si, destacam-se ethé de persistente e determinado, apresentando duas das disposições tratadas por Aristóteles (eúnoia e areté). Do auditório, evidenciam-se imagens de herói, admirável, respeitado e confiável. Pode-se dizer que as qualidades virtuosas do herói ajudam a 
contribuir para o sucesso da série que conquistou a adesão do público.

Os ethé evidenciados são reforçados também pelo discurso (logos), constituído pelos stills de imagens e pelos diálogos transcritos das cenas, os quais mostram que os ethé negativos do protagonista são construídos pré-discursivamente por representações estereotipadas, devido o mesmo possuir dentro de si o espírito da Raposa de Nove Caudas, responsável pela destruição da Folha. As análises desvelam ainda que Naruto reconstrói seu ethos pelo caráter destemido. A determinação pode ser observada a partir do discurso (logos) como um todo (stills das cenas e diálogos).

\section{REFERÊNCIAS}

ARISTÓTELES. Retórica. Trad. Manuel A. Júnior, Paulo F. Alberto e Abel N. Pena. São Paulo: Folha de São Paulo, 2015.

BRENNER, Robin E. Understanding manga and anime. London: Copyright, 2007. p. 1-12 CASTILHO, Ataliba Teixeira; PRETI, Dino (Orgs.). A linguagem falada culta na cidade de São Paulo: materiais para seu estudo, vol. I, Elocuções Formais. São Paulo: T. A. Queiroz, GARCIA, 1986.

EGGS, Ekkehard. Ethos aristotélico, convicção e pragmática moderna. In: AMOSSY, R. (Org.) Imagens de si no discurso: a construção do ethos. São Paulo: Contexto, 2005. p. 29-56.

FERREIRA, Luiz Antonio. Leitura e persuasão: princípios de análise retórica. São Paulo: Contexto, 2010. p. 17-21; p. 90-100.

FERREIRA, Luiz Antonio. Inteligência retórica e vocalidade: constituição e manutenção retórica. In: FERREIRA, Luiz Antonio (Org.). Inteligência Retórica: o ethos. São Paulo: Blucher, 2019. p. 9-18.

FIORIN, José Luiz. Argumentação. São Paulo: Contexto, 2015. p. 69-73.

MAINGUENEAU, Dominique. Problemas de ethos. In: POSSENTI, S.; SOUZA-E-SILVA, M. C. P. (Orgs.). Cenas da enunciação. São Paulo: Parábola, 2008. p. 55-73.

MAINGUENEAU, Dominique. Variações sobre o ethos. Trad. Marcos Marcionilo. São Paulo: Parábola, 2020.

MARTINS, Raul. Esse fã de Naruto mostrou que é o maior admirador do Sasuke do mundo. Fatos nerd, 2018. Disponível em <https://fatosdesconhecidos.ig.com.br/essefa-de-naruto-mostrou-que-e-o-maior-fa-de-sasuke-do-mundo/>. Acesso em: 22. set. 2020.

MEYER, Michel. Retórica. Trad. Marly N. Peres. São Paulo: Ática, 2007. 
NOBOA, GiselleVanessa Oñate. Impacto transcultural del anime Naruto en el contenido multimedia de la página de facebook "el tío naruto" en el período de julio 2018. 125f. Pontificia Universidad Católica del Ecuador Facultad de Comunicación, Lingüística y Literatura. Disertación a la obtención del título de licenciada en comunicación con mención en periodismo, Quito, 2019.

PARIS, Camila de. Esse é meu jeito ninja? Uma interpretação sociológica da escola ninja no mangá naruto através da teoria de Pierre Bourdieu. Trabalho de Conclusão de Curso de Graduação apresentado como requisito para obtenção de grau de Licenciada em Ciências Sociais da Universidade Federal da Fronteira Sul. Erechim, 2019.

PEREIRA, Ilíada Damasceno. Animencontro, visualidades e pedagogias culturais. In: Anais do I Encontro Nacional Deformação Docentes em Artes II Encontro Regional Sobre Formação de Professores Para o Ensino da Arte. Faculdade de Educação e Colégio de Aplicação Centro de Filosofia e Ciências Humanas Universidade Federal do Rio de Janeiro. Rio de Janeiro: Desfronteiramentos, 2011. p. 107-120. (PDF)

PERELMAN, Chaïm; OLBRECHTS-TYTECA, Lucie. Tratado de argumentação: a nova retórica. Trad. Maria E. A. P. Galvão. 3. ed. São Paulo: Martins Fontes, 2005. p. 16- 27.

REBOUL, Olivier. Introdução à retórica. Trad. Ivone C. Benedetti. São Paulo: Martins Fontes, 2004. p. 47-49.

TRINGALI, Dante. Introdução à retórica: a retórica como crítica literária. São Paulo: Duas Cidades.

Recebido em: 18/11/202

Aceite em: 01/12/2020 